Landshut, 1885; Geburt Christi, Vorarlberger Landesmus., 1887; Porträts: Präs. Ganahl, Vorarlberger Handelskammer; MiB Douglas, 1888-89; Kreuzabnahme, Kapuzinerkirche Feldkirch; Ausst. im Vorarlberger Landesmus.: Großmütterchen, Kartoffelernte, Landsknecht, Kühe in Grins, etc.

\section{L.: Thieme-Becker.}

Jeiteles Eleonore, Pädagogin und Schulgründerin. * Wien, 23. 5. 1841; † Wien, 12. 3. 1918. Lehrerin. Eröffnete 1873 eine dreiklassige Bürgerschule für Mädchen, die sie 1888 in ein Lyzeum umwandelte (höhere Mädchenschule, Mittelstufe zwischen den späteren Lyzeen und den Fortbildungsschulen - zweitälteste Schule dieser Art in Wien). J. übergab diese 1900 gegen eine bescheidene Ablöse an E. Schwarzwald. Sie hatte großes Interesse für Frauenfragen, war Leiterin der Unterrichtskomm. des Bundes österr. Frauenver. und redigierte die Statistik ,Die Unterrichtsanstalten für die weibliche Bevölkerung der im Reichsrate vertretenen Königreiche und Länder, 1908“،

L.: Der Bund, H. 3, 1918, S. 22; Frauenbewegung, Frauenbildung, Frauenarbeit in Osterr., hrsg. vom Bund österr. Frauenver., 1930, S. 24, 42; A. MayerH. Meißner-H. Sieß, Geschichte der österr. Mädchenmittelschule, Bd. 2, 1955, S. 57, 258.

Jeitteles Adalbert, Bibliothekar und Germanist. * Wien, 20. 8. 1831; † Graz, 28. 2. 1908. Sohn des Schriftstellers Andreas Ludwig J. (s.d.), Bruder des Zoologen Ludwig J. (s. d.); stud. in Wien Germanistik und wurde, nach kurzer Tätigkeit als Lehrer, Bibliothekar, 1859 an der Bibl. des Min. für Kultus und Unterricht, 1861 an der Univ.-Bibl. Wien, 1867 an der Univ.Bibl. Graz und 1871 Vorstand der Univ.Bibl. Innsbruck. 1868 Priv.Doz. für dt. Philol. an der Univ. Graz. 1881 i.R., lebte er seit 1890 in Graz. J. publizierte bibliothekar. wie philol. Untersuchungen, hier vor allem zur älteren dt. Philol.

W.: Grundzüge einer Reform der österr. Staatsbibliotheken, 1872; Die St. Pauler Predigten und Herr A. Schönbach, 1881; Justus Frey, ein verschollener österr. Dichter, 1898; etc. Hrsg.: K. A. Hahn, Althochdt. Grammatik, 3. Aufl. 1870; Aitdt. Predigten aus St. Paul, 1878; J. Frey, Ges. Dichtungen, 1899; J. Frey, Spruchdichtungen, 1903; etc. L.: Wr.Ztg. (Abendpost) vom 29. 2. 1908; Kürschner; Wurzbach; Blograph. Jb. 1910.

Jeitteles Alois Isidor, Schriftsteller und Mediziner. * Brünn, 20. 6. 1794; † Brünn, 16. 4. 1858. Vater des Eisenbahnfachmannes Richard J. (s. d.), Vetter des Folgenden; stud. in Prag, Brünn und Wien Med., 1819 Dr.med., ließ er sich nach ausgedehnten Studienreisen in Brünn nieder, 1848
Schriftleiter der amtlichen „Brünner Zeitung". Verfasser vielgespielter Lustspiele und des Liederzyklus "An die ferne Geliebte", den Beethoven (s. d.), der ihm freundschaftlich verbunden war, vertonte.

W.: Der Schicksalsstrumpf, gem. mit J. F. Castelli, 1818; Auge und Ohr, 1837; Der Liebe Wahn und Wahrheit, 1842; Moderne Walpurgisnacht, 1848; Ubers.: Calderon, Fegefeuer des hl. Patricius, 1824; etc.

L.: Wr.Ztg. vom 22.4.1858; Giebisch-PichlerVancsa; Kosch; Nagl-Zeidler-Castle 4, S. 1330; Hirsch; Wininger; Wurzbach; ADB; Mitt. H. Gumppenberg, Wien.

Jeitteles Andreas Ludwig, Ps. Justus Frey, Schriftsteller und Mediziner. * Prag, 24. 11. 1799; † Graz, 17. 6. 1878. Vetter des Vorigen, Vater des Germanisten und Bibliothekars Adalbert J. (s.d.) und des Zoologen Ludwig J. (s.d.); stud. an den Univ. Wien und Graz Med., 1825 Dr.med., 1829 Prosektor an der anatom. Lehrkanzel in Wien, 1835 Prof. an der Univ. Olmütz, 1842/43 Rektor, 1848 Abg. des Olmützer Wahlbezirkes im Frankfurter Parlament. Lyriker und Dramatiker nach dem Vorbild der Klassiker.

W.: Elemente der Anthropophysiol. aus dem Standpunkt der fortgeschrittenen Wiss., 1838; Auch ein Wort über den Kampher, in: Med. Jbb. des k.k. österr. Staates, Bd. 22, 1840, S. $105 \mathrm{ff}$.; Aufforderung zur Begründung einer vergleichenden Psychol. und Zoopsychol., ebenda, S. 177 ff.; Hist. über Reflexbewegung, in: Prager Vierteljahrschrift für prakt. Med., 1858; Gibt es eine Knochensyphilis oder sind die in der Syphilis auftretenden Knochenleiden Produkte des Quecksilbergebrauches? 1862; Dichtungen, 2 Bde., 1894; Ges. Dichtungen, hrsg. von A. Jeitteles, 1899; Spruchdichtungen, hrsg. von A. Jeitteles, 1903; etc.

L.: A. Jeitteles, Justus Frey, ein verschollener osterr. Dichter, 1898; Giebisch-Pichler-Vancsa; Kosch; Nagl-Zeidler-Castle, s. Reg.; Hirsch; Wininger; Wurzbach; $A D B$ 50.

Jeitteles Isaac, Mediziner. * Prag, September 1779; † Prag, 23. 11. 1852. Sohn eines Arztes; stud. Med., 1800 Dr.med., übernahm 1806 die väterliche Praxis; 1831 wurde ihm die Leitung des Choleraspitales im Prager Judenviertel übertragen. Bei diesem Anlaß stiftete J. dem med. Doktoren-Collegium der Univ. Prag für erwerbsunfähige Mitglieder und deren Familien 10.000 Gulden. 1850 k. Rat. J. ging bei Stellung seiner Diagnosen von direkten Beobachtungen der Kranken aus und stellte zahlreiche Forschungen über die Wirkung der böhm. und mähr. Heilquellen an.

W.: Heilresultate durch die bøhm. Mineralquellen, in: Jbb. für Deutschlands Heilquellen und Seebäder, 1836, Jg. 1, S. $383 \mathrm{ff}$.; Heilresultate erreicht durch den Gebrauch der Quellen von Carlsbad und 